\title{
Studying the Properties of Porous Alumina Using Starch as a Binder
}

\author{
Hazim K. Alag ${ }^{1 *}$ and Rafid Sabbar Zamel ${ }^{2 * *}$ \\ ${ }^{1}$ Al-Mutameizeen Secondary School, Karkh the second-Ministry of Education, Baghdad-Iraq. \\ ${ }^{2}$ Department of Applied Science, University of Technology, Baghdad, Iraq. \\ *Corresponding Author: h.alack@yahoo.com \\ *** Corresponding Author: rsz_81@yahoo.com
}

\begin{abstract}
This work is concerned with the preparation of alumina porous ceramic, the effect of binder (corn starch) and sintered on the physical and mechanical properties of ceramic bodies were. In this work porous raw material ceramic have been produced by using natural additive (corn starch) with $(0,5,10,15) \mathrm{wt} \%$. The mixture were dried at $80^{\circ} \mathrm{C}$ for 2 hours. These samples were sintered at $1000^{\circ} \mathrm{C}$. Many mechanical properties tests were used to determine the properties of prepared ceramic material which involves: the linear shrinkage, water absorption, apparent porosity, diametrical compression strength, scanning electron microscope (SEM) and $\mathrm{x}$-ray diffraction (XRD). The results show the interconnected pores between $(10-25 \mu \mathrm{m})$ without additive, $(15-28 \mu \mathrm{m})$ at $5 \mathrm{wt} \%,(17-35 \mu \mathrm{m})$ at $10 \mathrm{wt} \%$ and $(20-55 \mu \mathrm{m})$ at $15 \mathrm{wt} \%$. The pore size are illustrated by small and large spherical shape the corn starch particle, which are connected and contain an interconnected pores throughout small pores channels.

[DOI: $10.22401 / \mathrm{JNUS} .21 .3 .13$ ]
\end{abstract}

Keywords: Bioceramic, Alumina, Binder.

\section{Introduction}

Porous ceramic are widely applied in different fields, ranging from light-weight structures and thermal or acoustic insulation to catalysts supports, membrane, fillers bioceramic and others [1-3]. One of the basic method to produced porous ceramic is by pore foaming agents. e. g. starch [4]. Moreover, during the last few years it has been recomizer that starch content not only as a pore foaming agent but also as a (consolidation) in a new process called starch consolidation casting (SCC) [5]. There are a lot of concerns have been put in order for the researches to consider the best way to responds to the demand on the biomaterials products science there are a lot of shortcomings derived from allograft and auto graft as a bone substitute. They tried to discover as simple as possible method plus reducing in cost as an advantage. Besides the usage of environmental-friendly materials should also be considered as it becomes the main concern nowadays. Then again, the produced artificial bones must meet several critical before it can be applied to human body [4].

\section{Literature Review:}

Many studies have demonstrated that hydroxyapatite (HA), tri-calcium phosphate (TCP), $3 \mathrm{Y}-\mathrm{ZrO}_{2}$, alumina, and bioactive glasses can improve the formation of a bonelike apatite layer on their surfaces. The inorganic ceramic phase can be combined with proteins and starches binders to produce bioactive and biodegradable composition. Ribeiro, et.al, used an ovalbumin amounts (5-7wt \%) were added to the ceramic slurries (TCP) and suspension with a solid percentage higher than $60 \mathrm{wt} \%$ were obtained. The foam was produced by mechanical stirring. The result that the presences of the surfactant increasing the volume and stability of the foam [6]. Almeida, et.al, studied the effect of corn starch and sintered on the preparation of ceramic bodies. The process was done by using consolidation casting method. The gel point were determined by rheological analysis [7]. Porous $3 \mathrm{Y}-\mathrm{ZrO}_{2}$ ceramics were produced by using two types of starch (corn and potato). The aqueous suspensions of the different ceramic mixtures were thermally consolidated and the effect of the type and the quantity of binder added on the resulting dried [8]. 


\section{Binders}

When a low ceramic content is employed to increase the porosity, cracks are prone to occur in the sample, because of shrinkage during sintering, which, consequently, causes a severe reduction in strength. So in most of the previous experiments, use of binder is a requisite for sintering ceramic. Polymers and proteins are usually used as the binder, since it will be expected to improve the strength of the green body, which in turn, would prevent cracking [9]. The presence of small pores formed by the removal of the polymer on the ceramic during sintering. The polymer could also be used to increase ceramic's porosity [10].

\section{Raw material}

Alumina $\left(\mathrm{Al}_{2} \mathrm{O}_{3}\right):($ Spain)(DIDACTIC)

Alumina ceramic has bio inertness [5]. Calcium Carbonate:(England) (University of Technolog/Applied Science / Chemistry Lab.)

\section{Starches}

Starches is a pore forming agent due to its properties which are their gelling ability in water, their thickening, adhesive and film forming abilities [11]. The starch properties are widely used because that they are environmental friendly, easy to fire out and inexpensive [12].

\section{Corn starch}

A commercial corn starch used had not any physical or chemical modification. It was chosen mainly due to its low cost and easy reproducibility that can simultaneously act as a binder during the formation of ceramics by a starch consolidation casting method [13].

\section{Buffers}

The quality of fixation is effect by using $\mathrm{pH}$ and the type of ions present. The select of buffer is based on:

1.The $(\mathrm{pH})$ range with an ability to get a constant $(\mathrm{pH})$ during fixation.

2.Neither swell nor shrink.

3.The toxicity of the buffer.

Disodium hydrogen phosphate $\left(\mathrm{Na}_{2} \mathrm{HPO}_{4}\right)$ It is a white powder that is highly hygroscopic and water soluble [14]. sodium hydrogen phosphate or sodium phosphate dibasic. It is commercially available in both the hydrated and anhydrous forms [6].

\section{Preparation methods:}

The obtained powder from the stone of chemical laboratory is $\left(\mathrm{Al}_{2} \mathrm{O}_{3}\right.$ and $\left.\mathrm{CaCo}_{3}\right)$ as shown in Figures (9 and 10) denoted the X-ray diffractions of the powders before and after firing. The calcium carbonate and the alumina with particle size $(143.6 \mathrm{~nm})$ and $(63.58 \mathrm{~nm})$ respectively, which used in this work to prepare the porous ceramic as shown in Fig.(7). The porous ceramic samples were prepared by consolidation casting method. Different corn starch composition as shown in Table (1) with wt\% of corn starch were added to the aqueous suspension obtained from dissolving $\mathrm{Na}_{2} \mathrm{HPO}_{4}$ in water with ratio $0.35 \mathrm{~g} / \mathrm{mL}$ with continuous mixing to get stabilize foam.

Table (1)

The wt\% of ceramic mixture.

\begin{tabular}{|c|c||c||c||}
\hline $\begin{array}{c}\text { Mixing } \\
\text { symbol }\end{array}$ & $\begin{array}{c}\text { Alumina } \\
\text { mixture } \\
\text { wt\% }\end{array}$ & $\begin{array}{c}\text { The binder } \\
\text { powder } \\
\text { (corn starch) } \\
\text { wt\% }\end{array}$ & $\begin{array}{c}\mathbf{N a}_{2} \mathbf{H P o}_{4} \\
\text { wt\% }\end{array}$ \\
\hline \hline A & 98 & 0 & 2 \\
\hline \hline B & 93 & 5 & 2 \\
\hline C & 88 & 10 & 2 \\
\hline D & 83 & 15 & 2 \\
\hline
\end{tabular}

The foam were poured in the mold. The foams prepared from corn starch were kept in oven at $80^{\circ} \mathrm{C}$ for 2 hours.

The samples are in cylindrical form, with a dimension of (23-24 mm) diameter and $(5-7 \mathrm{~mm})$ thickness, were dried at room temperature and then at $100^{\circ} \mathrm{C}$ until there was no further change in mass. A firing samples prepared with corn starch were achieved by slow heating at $1000^{\circ} \mathrm{C}$ using a heat rate $5^{\circ} \mathrm{C} / \mathrm{min}$, and soaked for 2 hours.

\section{The aim of this project:}

1. Manufacturing porous ceramic material as bone substitute.

2. Study the effect of natural binders on the physical properties.

3. Study the effect of sintering temperature on the physical properties.

Measurement of physical properties: 


\section{Water absorption}

The amount of water absorbed is a function to the total porosity, and accessibility of the pore system, porous ceramics of great capillary action can hold a large volume of water [15]. Water absorption depends on the properties of the raw material, the size of aggregates, the degree of orientation of the structure, shaping process and firing condition [16]. Water absorption test cannot differentiate sharply between completely vitrified pieces and those with a few number of interconnected pores. The detection of less absorption by immersed pices in dye solution. Evacuation to penetration of the dye into any pores present. Any dye absorbed can be seen if a piece is broken open [16]. Water absorption expresses as a percentage of the relationship of the weight of water absorbed to the weight of the dry specimen as follow [17]:

$$
W \cdot A \cdot \%=\frac{(\mathrm{S}-\mathrm{D})}{\mathrm{D}} * 100 \%
$$

Where:

S: Saturated weight (Socked weight) (g).

D: Dry weight of specimen (g).

\section{Apparent porosity (A.P)}

The physical properties of samples were measured by the standard test method [ASTM C20-83]. Apparent porosity was measured by boiling water technique.

$$
\text { A.P. } \%=\frac{(\mathrm{S}-\mathrm{D})}{(\mathrm{S}-\mathrm{I})} * 100
$$

Where:

S: Saturated weight (Socked weight) (g).

D: Dry weight of specimen (g).

I: weight of the soaked immersed piece $(\mathrm{g})$.

\section{Mechanical properties calculation}

Calculations of mechanical properties especially compressive strength of samples are essential for their applications.

\section{Diametrical Compressive strength}

This test was performed on disks having an average $(17-22 \mathrm{~mm})$ diameter and $(6-7 \mathrm{~mm})$ height, using a compression test device INSTRON 1195, the sample was fixed between the upper and lower platens of the device to start compression at a rate (cross- head speed $=0.5 \mathrm{~mm} / \mathrm{min}$ ) until fracture occurs. Fracture strength $\left(\delta_{\mathrm{F}}\right)$ was determined by applying the equation:

$$
\delta=\frac{2 \mathrm{p}}{\pi D t}
$$

Where:

$\delta$ : The fracture strength (Pascal).

$\mathrm{p}$ : The applied load(Newton) .

$\mathrm{D}$ : The sample diameter $(\mathrm{m})$.

$\mathrm{t}$ : The thickness of sample (m) .

Microstructure characterization

\section{Scanning Electron Microscope (SEM)}

Microstructure examination was carried out on the sintered specimens by using "Hitachi-s-4160 scanning electron microscope" equipped with secondary electron image (BEI). All specimens were coated with gold for $\left(6\right.$ minutes) to a thickness of $\left(480^{\circ} \mathrm{A}\right)$ using "physical vapor deposition "method by an Argon ion (plasma) at working pressure [300mTors] for examination in the scanning electron microscope.

\section{X-ray Diffraction}

X-ray diffraction analysis was performed for the fired samples using X-ray vertical diffract meter type [RIGAKU, MINIFLEX2] made in Japan, for $\mathrm{Cu} \lambda=1.5406^{\circ} \mathrm{A}$, power 30 $\mathrm{KV} / \mathrm{mA}$. A complex ceramic material would usually analyzed by using the powder technique, the selected specimen were milled by using mortar, a line pattern is obtained from the chart containing the characteristic reflections from each mineral present. A comprehensive index of the d-spacing for all known minerals has been drawn up by the American Society for Testing Materials and it's by reference to that the minerals present in an unknown material may be identified. From the d-spacing and relative intensity of different line (consider the highest peak represents $100 \%$ of the intensity), we can identify the presented phases in each sample.

\section{Results and Discussions Water absorption}

Fig (1) for a corn starch binder at $1000^{\circ} \mathrm{C}$ it shows that the water absorption values increase with increasing starch content due to the increasing in the starch particle volume arising from swelling which produce the 
increasing in a pore size as shown in Fig(SEM). The overlapping of starch grains in a green body leads to interconnected pores thereby increases in an apparent porosity at a sintering an object, agreement with [18].

\section{Apparent porosity}

Fig.(2) shows the apparent porosity values of the samples prepared by using corn starch additive. From the figure, it was observed that the apparent porosity at $1000^{\circ} \mathrm{C}$ increase with increasing starch content as for the same reason of water absorption.

\section{Linear shrinkage}

Fig.(3) shows the linear shrinkage values of samples prepared with corn starch additive at sintering temperature $1000^{\circ} \mathrm{C}$. It was observed from the figure that the linear shrinkage increasing with increasing starch content. The sintered shrinkage was depend on a starch content at a raw material (Alumina and calcium carbonate), and the increasing in shrinke with increase sintered due to remove some empty spaces existing between the matrix particles, agreement with [18].

\section{Diametrical Compressive strength}

Fig.(4) shows the diametrical compressive strength values of samples prepared with corn additive at $1000^{\circ} \mathrm{C}$ sintering temperature. It was observe from the figure that the diametrical compressive strength decrease with increasing the starch content. This behavior may be attribute to the high porosity which tends to decrease the density of material and thus the compressive strength values.

\section{Scanning Electron Microscope (SEM):}

The microstructures of sintering samples in a high temperature are shown in Figures prepared without and with corn starch respectively at $1000^{\circ} \mathrm{C}$. Fig.(5) illustrates the resulting microstructure of samples prepared without additives. It is clearly that the fracture surface has fine pores even when X150 magnification is used, the pores weren't observed with a pore diameter (10-25) $\mu \mathrm{m}$. Fig.(6) shows the images of the fracture surface of samples prepared with corn starch additive. A high percentage of interconnected pores were uniformly distributed within the surface with irregular shape like honeycomb with pore diameters (15-28) $\mu \mathrm{m}$ when the magnification is X700. The effect of sintering temperature on the sample structure prepared with corn starch addition is shown in Fig.(7) when the magnification is X800. the necks between the alumina and the calcium carbonate grains is appeared, small regions of a high densification grains dissolved in each other and interconnected pores are also appeared. It was observed low percentage of small pores are eliminated resulting low porosity when the magnification X1000.

\section{X-ray diffraction}

It is well known that X-ray diffraction technique is a powerful tool to determine the crystalline phases present in the samples. These samples in our work were prepared and studied under the same conditions. Fig.(9) and (10) show the X-ray diffraction pattern of the powder taken from the market before and after heat treatment respectively. The two figures shows alumina and calcium carbonate and there are no change in phases, and the two phases are identical. Alumina and calcium carbonate were indexed according to (JCPDSICDD PDF \# 210130).

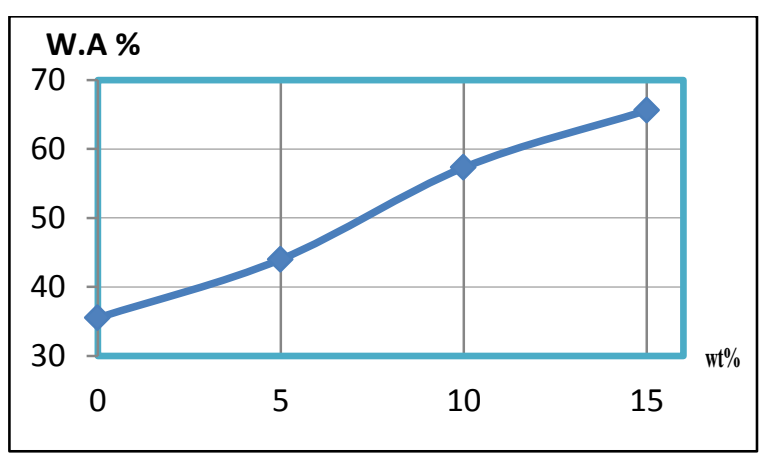

Fig.(1): The water absorption of samples prepared with corn starch at $1000^{\circ} \mathrm{C}$.

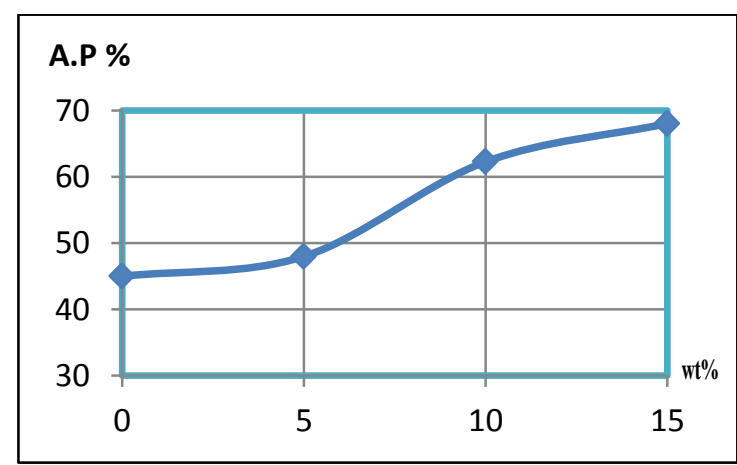

Fig.(2): The apparent porosity of samples prepared with corn starch at $1000^{\circ} \mathrm{C}$. 


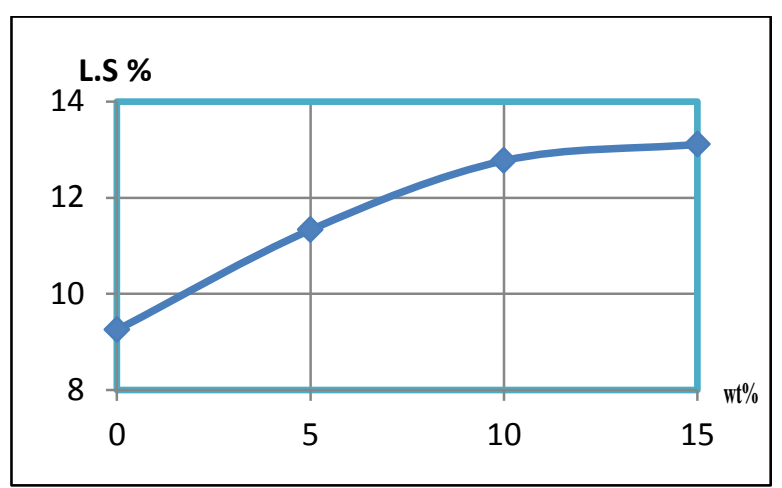

Fig.(3): The linear shrinkage of samples prepared with corn starch at $1000^{\circ} \mathrm{C}$.

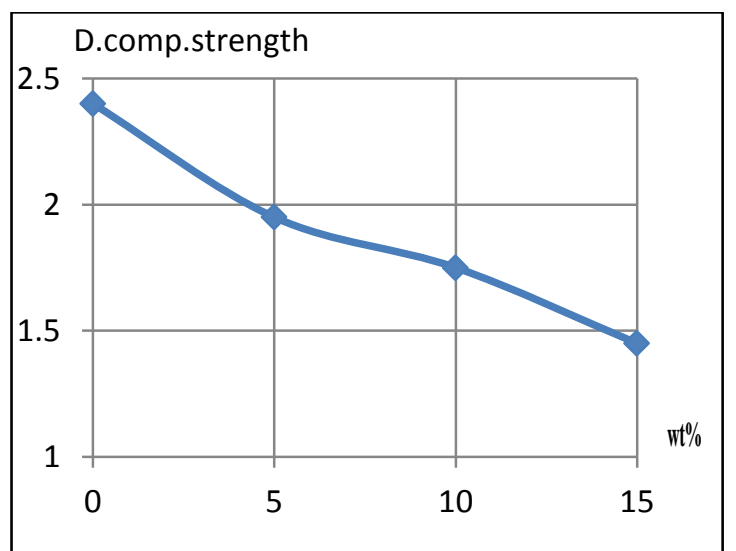

Fig.(4): The diametrical compressive strength of samples prepared with corn starch at $1000^{\circ} \mathrm{C}$.

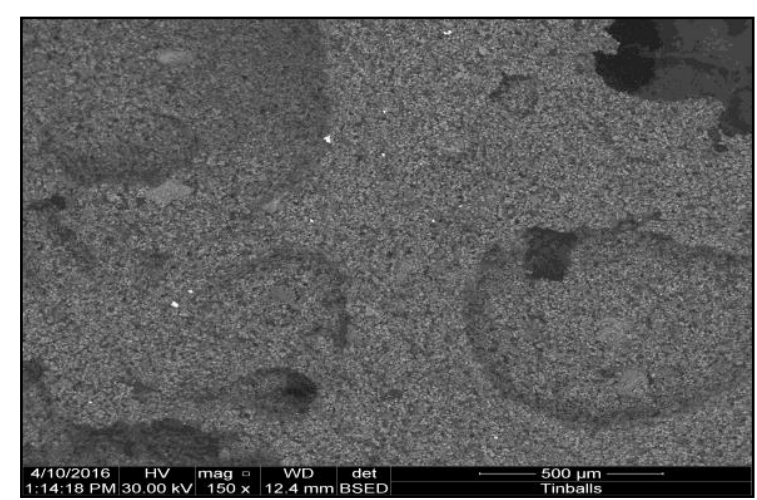

Fig.(5): SEM of sample prepared without additive at $1000^{\circ} \mathrm{C}$.

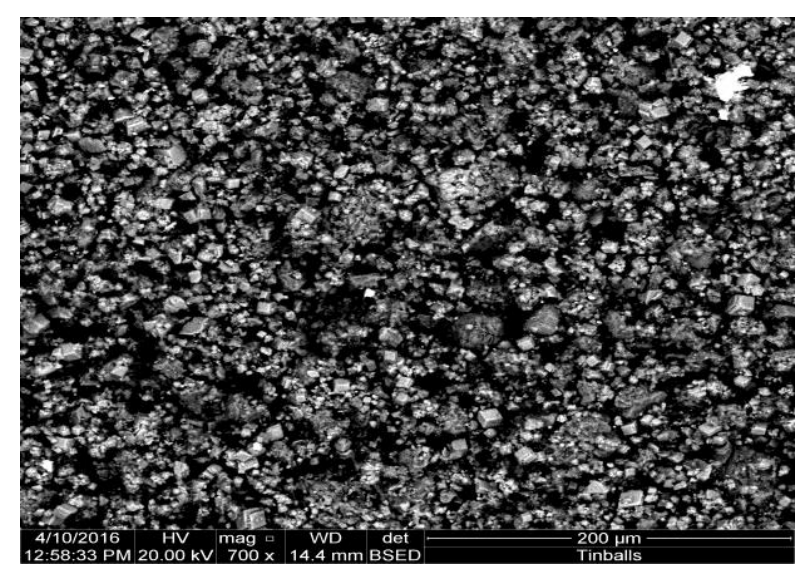

Fig.(6): SEM of sample prepared with 5wt\% of corn starch binder at $1000^{\circ} \mathrm{C}$.

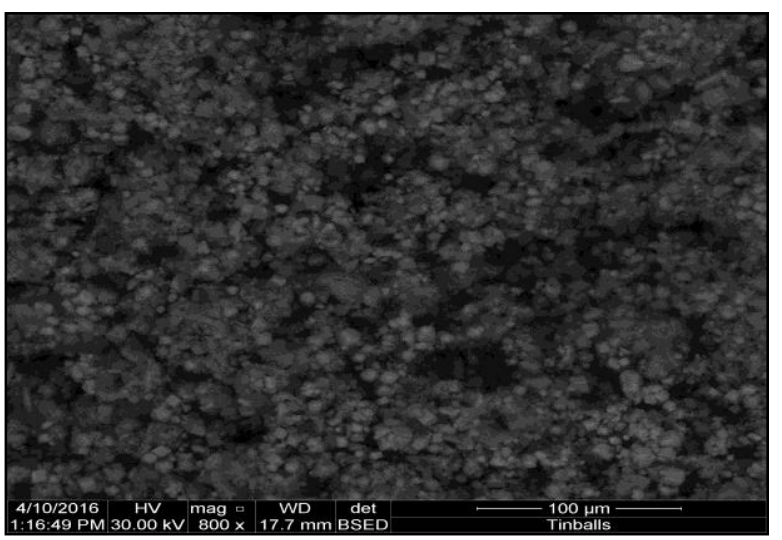

Fig.(7): SEM of sample prepared with 10wt\% of corn starch binder at $1000^{\circ} \mathrm{C}$.

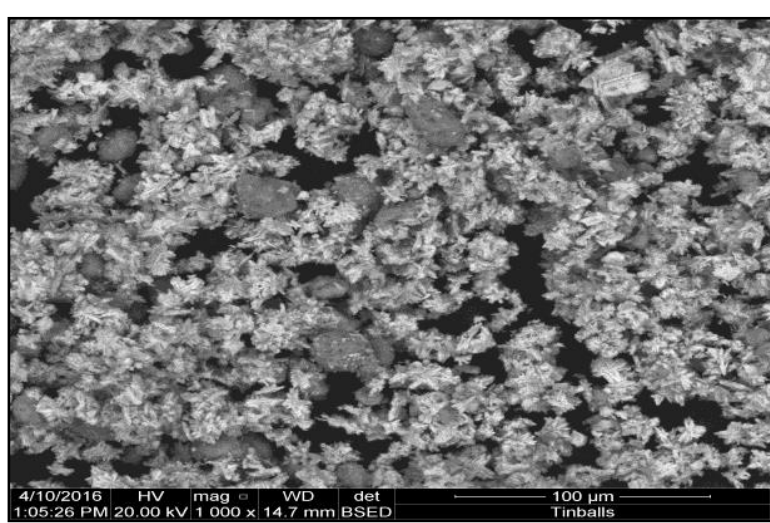

Fig.(8): SEM of sample prepared with $15 w t \%$ of cornstarch binder at $1000^{\circ} \mathrm{C}$. 


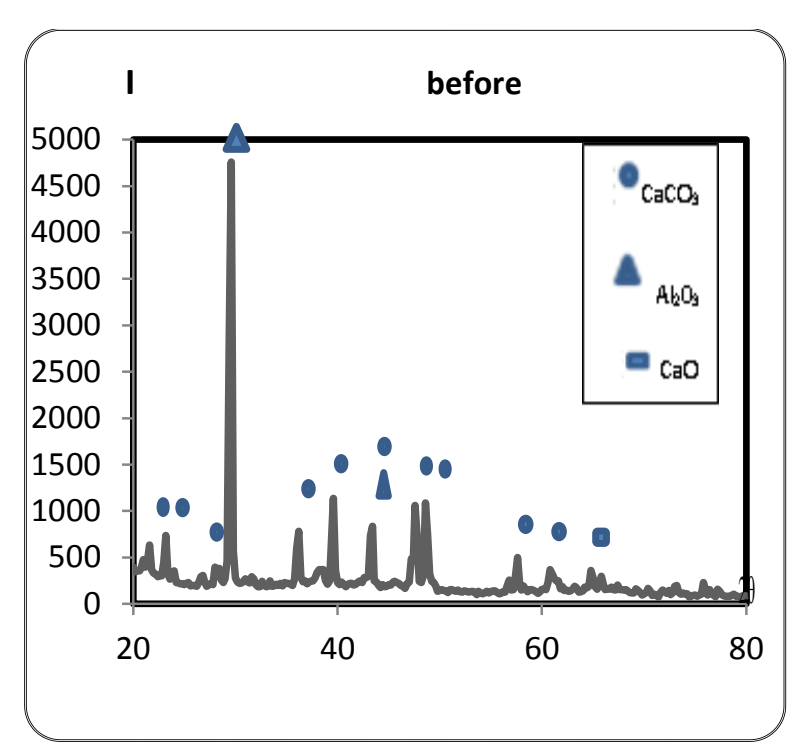

Fig.(9): The XRD of samples before firing.

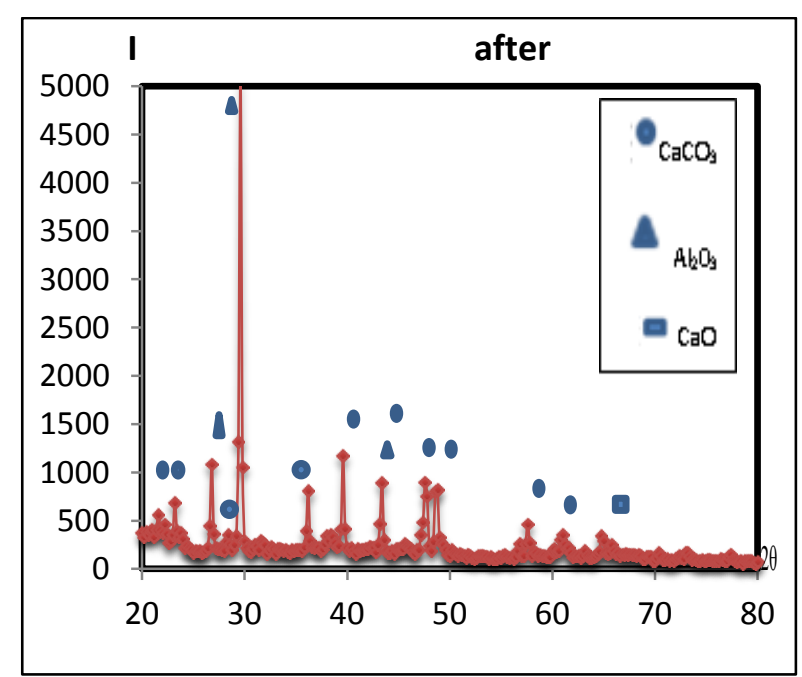

Fig.(10): The XRD of samples after firing.

\section{Conclusions}

The conclusions of this work can summarized:

1.Porous ceramic [Alumina and Calcium carbonate] prepared with corn starch binder is a suitable material to produces samples with a good distribution to the pores.

2.The micrograph of samples prepared with corn starch reveals that the structure contain as closed pore with a small presence of an interconnected pores which increased with increasing corn starch contents.

\section{References}

[1] Liu D.M. (ed.): Porous Ceramic Materials. Trans Tech Publications, Aedermannsdorf, 1-240, 1996.
[2] Liu D.M., Dixit V.(eds.): Porous Materials for Tissue Engineering. Trans Tech Publications, Aedermannsdorf, 1-242, 1997.

[3] Schüth F., Sing K.S.W., Weitkamp J. (eds.): Handbook of Porous Solids (Volumes 1-5). Wiley-VCH, Weinheim, 4, 1-3141, 2002.

[4] Mattern A., Huchler B., Staudenecker D., Oberacker R., Nagel A., Hoffmann M.J.: Preparation of Interpenetrating Ceramic Metal Composites J. Eur. Ceram. Soc. 24, 3399-3408, 2004.

[5] Chiroff T., White E. W., Webber J. N.. And Roy D., "Tissue lngrowth of Replamineform Implants", J Biomed. Mater Res Symp, 6, 29-45, 1975.

[6] Ribeiro C., Bressiani J. C., and Bressiani A. H. A., "Characterization of the Calcium Phosphate Porous Ceramic Obtained by Foam Consolidation using Albumin", Key Engineering Materials, 361-363,971-974, 2008.

[7] Almeida F.A., et.al, "Influence of cassava starch content and sintering temperature on the alumina consolidation technique", Journal of the European Ceramic Society 29. 1587-1594. As downloaded by IVSL, 2009.

[8] Hae-Won Kim, Jonathan C. Knowles, and Hyoun-Ee Kim, "Hydroxyapatite and gelatin composite foams processed via novel freeze-drying and crosslinking for use as temporary hard tissue scaffolds", School of Materials Science and Engineering, Seoul National University, Seoul 151-742, Korea, 2004.

[9] Nishikawa M, Myoui A, Ogushi H, Ikeuchi M, Tamai N, Yoshikawa H., "Bone tissue engineering using novel interconnected porous hydroxyapatite ceramics combined with marrow mesebchymal cells: Quantitative and three-dimensional image analysis", Cell Transplant, 13, 367-376, 2004.

[10] Ramay H.R. and Zhang M.Q., "Preparation of porous hydroxyapatite scaffolds by combination of the gel-casting and polymer sponge methods. Biomaterials", 24, 3293-3302, 2003.

[11] Eleasar Martins Marins, et.al. "Commerical starch consolidation technique for shaping Silicon Carbide (SiC) 
ceramics", 17th International congress of mechanical Engineering, SaoPaulo, SP, eleasar@lcp.inpe.br, 2003.

[12] Liliana B. G., et.al, "Influence of Starch Type on Characteristics of Porous $3 \mathrm{Y}-\mathrm{ZrO}_{2}$ Prepared from a Direct Consolidation Casting Method" Materials Research, As downloaded by IVSL, 14(1), 39-45, 2011.

[13] Gregorova E, Zivcova Z and Pabst W., "Porosity and pore space characteristics of starch-processed porous ceramics", Journal of the Materials Science., 41, 6119-6122, 2006.

[14] Ginebra MP, Fernández E, Driessens FCM, Planell JA., "The effect of $\mathrm{Na}_{2} \mathrm{HPO}_{4}$ addition on the setting reaction kinetics of an a-TCP cement", In: LeGeros RZ, LeGeros JP, eds., Bioceramics Vol. 11 (Proceedings of the 11th International Symposium on Ceramics in Medicine), New York: World Scientific Publishing Co. Pte. Ltd, 243-6,1998.

[15] Hanny, N.B., "solid state Chemistry", Prentice-Hall, Inc., New Jercy, 1967.

[16] Durrant P.J., "General and inorganic Chemistry", Butle and Tanned, London, 1962.

[17] ASTM Annual Book of standards, 15(01), 251-253 1989.

[18] Kahtan Al-Khazraji, "Effect of sintering on some Physical and mechanical properties of fabrication hydroxyapatite used for hard tissue healing", Eng. and Tech. Journal, 28(10), 11-15, 2010. 